\title{
"A Bela e a Fera ou a Ferida Grande Demais", de Clarice Lispector: transtextualidade e transcriação
}

\author{
Luciene Guimarães de Oliveira
}

\begin{abstract}
Resumo
A partir do corpus literário constituído pelos contos "A Bela e a Fera ou a ferida grande demais", de Clarice Lispector, "Uma xícara de chá" de Katherine Mansfield, do conto de encantamento "La Belle et la Bête", e do filme de Jean Cocteau A Bela e a Fera, articula-se a teoria da transtextualidade, desenvolvida pelo francês Gérard Genette, com o conceito de transcriação, de Haroldo de Campos.
\end{abstract}

Palavras-chave: Clarice Lispector. Katherine Mansfield. Jean Cocteau. Transtextualidade. Transcrição.

Numa crônica publicada no livro $A$ descoberta do mundo, a escritora Clarice Lispector, indagada sobre qual seria o primeiro livro de sua vida, diz que prefere falar sobre o "primeiro livro de cada uma de minhas vidas" (LISPECTOR, 1999, p. 425). Um primeiro gosto literário foi experimentado com alguns contos de encantamento. Em outra vida que teve, aos 15 anos, Clarice se depara com o texto da escritora neozelandeza Katherine Mansfield e, a partir de então, não consegue deixar de exprimir uma admiração pela vida e obra dessa escritora. Uma afinidade literária manifestada em cartas, entrevistas, depoimentos, além da crônica citada. No último ano de vida, Clarice parece resgatar algumas dessas "vidas" ao escrever seu último conto, em 1977, publicado em 1979, depois de organizado por Olga Borelli: "A Bela e a Fera ou a ferida grande demais".

A partir do título, já se indicia um conto de encantamento: "A Bela e a Fera" ou "La Belle et la Bête", de Jeanne-Marie Leprince de Beaumont. Avançando um pouco mais na leitura do conto de Clarice, outro texto se insinua, quando se entrevêem traços do conto de Katherine Mansfield "A cup of tea", traduzido no Brasil em seu sentido literal: "Uma xícara de chá". Clarice retoma, então, em seu último conto, textos das "vidas" que teve: o conto de encantamento e um texto da escritora naturalizada inglesa, uma rara afinidade assumida no decorrer de sua carreira.

O teórico francês Gérard Genette associa a retomada a outros textos à imagem de um palimpsesto: um pergaminho utilizado na antigüidade, quando o processo de escrita fazia-se por superposição. Nas camadas de um palimpsesto, "uma primeira inscrição foi raspada para se traçar outra, que não a esconde de fato, de modo que se pode ler por transparência, o antigo sob o novo" (GENETTE, 2005, p. 5). Na concepção 
de Genette, a imagem de um palimpsesto representa todas as obras derivadas de uma obra anterior, configurando uma literatura de segunda mão em que um texto pode sempre ler um outro. No campo literário, um hipertexto é o resultado de uma reescrita a partir de um texto primeiro denominado por sua vez, de hipotexto. Essa relação hipertextual é um dos procedimentos que Genette chamou de "transtextualidade", ou "transcendência textual do texto," definida como tudo que o coloca em relação manifesta ou secreta com outros textos" (GENETTE, 2005, p. 7). Dessa perspectiva, em "A Bela e a Fera ou a ferida grande demais", como na imagem de um palimpsesto, entrevêm-se, sob o texto de Clarice, os contos de Beaumont e de Katherine Mansfield, tomados, assim, como hipotextos.

Por outro lado, ao escrever um texto a partir de outro, está-se também numa operação tradutora. O teórico russo Roman Jakobson categorizou as formas de tradução, não só de uma língua para outra (interlingual), como também de um meio para outro (intersemiótico) ou no âmbito de mesma língua (intralingual). O poeta e crítico Haroldo de Campos, ao tratar da tradução criativa, denominou-a de transcriação - forma de traduzir um texto poético que acaba por escapar à fidelidade, ao sentido literal, configurando então, na transgressão ao texto de partida, uma recriação, uma reescrita, um novo texto. Nesse sentido, pode-se dizer que "A Bela e a Fera ou a ferida grande demais" transcria o conto de Beaumont, escreve novamente esse texto de uma forma criativa, renova-o sob o olhar do século XX.

Publicado primeiramente em 1756, o conto de encantamento "La Belle et la Bête", já foi retomado inúmeras vezes, por diversos sistemas semióticos, inclusive pelo cinema, num filme dirigido por Jean Cocteau, em 1946 - um clássico do cinema francês. Tal filme foi citado por Jean-Luc Godard, em seu livro Introdução a uma verdadeira História do Cinema, como um dos que fizeram história. Jean Cocteau, que, numa época de pós-guerra, trouxe para as telas do cinema francês a magia do conto de encantamento, forjou o que ele chamou de "realismo irreal" - fazer valer, através da linguagem cinematográfica, o mágico e o fantástico de um conto de fadas, façanha tentada anteriormente nos primórdios do cinema pelo mágico Georges Meliès. Cocteau, que reunia outros talentos além do de cineasta como os de desenhista, escultor e poeta, também se valeu da arte pictórica dos pintores holandeses do século XVII Jan Vermeer e Pieter de Hooch e das ilustrações de Gustave Doré feitas para os contos de Perrault através de uma alusão a esses universos, em favor de uma poética da magia - apresentado sobretudo, no jogo de luz e sombra.

\begin{tabular}{|c|c|}
\hline $\begin{array}{c}\text { http://www.artinthepicture.com/artists/Jan_Vermeer/g } \\
\text { irl_thumb.jpg }\end{array}$ & $\begin{array}{c}\text { http://www.textanalyse.dk/Billeder/Vermeer\%20Kon } \\
\text { trast\%201.jpg }\end{array}$ \\
$\begin{array}{c}\text { FIG. 1-Moça com brinco de pérola. (Girl with a pearl } \\
\text { earring), (1645).Òleo sobre tela de Jan Vermeer. }\end{array}$ & $\begin{array}{c}\text { FIG.2 - A leiteira (Die milkmaid) (1658). Óleo sobre } \\
\text { tela de Jan Vermeer }\end{array}$ \\
Acesso em 6 dez. 2006. & Acesso em 6 dez. 2006. \\
\hline
\end{tabular}

A partir do corpus literário constituído pelos contos de Clarice Lispector, Katherine Mansfield, Beaumont e o filme de Jean Cocteau, articulamos a correlação entre transcriação e a transtextualidade, procedimentos nos quais podemos perceber em comum uma poética da reescrita. Uma poética consumada de um lado pela transgressão ao texto de partida, e do outro, pela literatura de segunda mão, uma literatura que deriva de si mesma. Desse corpus literário utilizado, compreende-se que "A Bela e a fera ou a ferida grande demais" é uma transcriação do conto de fadas ao 
mesmo tempo que mantém uma relação hipertextual com o conto "Uma xícara de chá".

Nessa relação hipertextual, percebemos que, nos contos de Clarice e Mansfield, o destino faz esbarrar, por acaso dois seres de mundos opostos, de classes distintas e situados em extremos estéticos. Em "A Bela e a Fera ou a ferida grande demais", uma mulher da alta sociedade carioca que esperava seu chofer na saída do salão de beleza depara-se subitamente com um mendigo, apoiado em muletas, que ostentava numa única perna, uma ferida. Já no conto "Uma xícara de chá", Rosemary Fell, uma obstinada consumista, saía de uma de suas compras quando se depara com uma mendiga que timidamente pede a ela um trocado para uma xícara de chá. Se no conto de Beaumont, Bela se assusta ao avistar a Fera pela primeira vez, tanto Rosemary Fell, do conto de Mansfield, quanto Carla de Souza e Santos, do conto de Clarice, ficam surpresas diante da figura de um mendigo. Ambas, no entanto, conseguem superar o medo: Rosemary Fell, em "Uma xícara de chá", tenta tornar-se uma espécie de fadamadrinha da mendiga, enquanto que em "A Bela e a Fera ou a ferida grande demais", Carla, protagonista do conto de Clarice, entra em crise existencial ao tomar consciência de sua alienação diante da vida.

$\mathrm{Na}$ transformação do conto de fadas que acontece em "A Bela e a Fera ou a ferida grande demais", um dos temas - a beleza - tem relevância na história de Carla, que a associava a seu sucesso, advindo de um promissor casamento com um banqueiro. O mesmo tema é entrevisto em "Uma xícara de chá", pois Rosemary Fell era insegura de sua beleza.

Percebemos também uma separação entre dois mundos. No filme de Cocteau a fotografia que contrasta o claro e escuro parece ser utilizada como linguagem que exprime a harmonia de uma beleza física e a angústia da Fera. No conto de fadas esse distanciamento acaba por ser diluído pela união das virtudes. Já no conto de Clarice, o distanciamento entre os personagens é demonstrado pela incomunicabilidade - o que cada um pensa é restrito ao seu íntimo - e pela drástica realidade social que os separa. É ainda por uma ferida de alma e pela miséria que se dá a intercessão desses dois mundos.

O título proposto, "Fera ou ferida" reserva toda uma carga de poesia e ambigüidade: de um lado, uma Fera (supostamente o mendigo) que traz consigo uma ferida, uma lesão física; e do outro lado, uma mulher que descobre uma "grande ferida de alma", uma vida sustentada por aparências, baseada na superficialidade de sua beleza e repleta de festas e vazio existencial. Entrevê-se o poético, quando se constata a ambigüidade da miséria: uma miséria que não dizia respeito apenas à realidade do mendigo, mas que conota também uma imperfeição, uma fraqueza, o vazio da vida de Carla, uma miséria de alma, uma alma maltrapilha.

O conto de Clarice e o filme de Cocteau transcriam a magia do conto de fadas de diferentes maneiras. No conto de Beaumont a magia de uma fada havia castigado um príncipe que foi convertido em fera: quebrar o encanto só se tornaria possível através de uma outra magia, que seria aquela da manifestação do amor. No filme de Cocteau, a magia é a essência de todo o filme. Na transcriação realizada pelo cineasta francês, a última fala do príncipe revela que ele fora encantado porque "os pais não acreditavam em magia". Já no início do filme, projeta-se na tela um texto em que o cineasta solicita ao público um pouco "da inocência infantil" e que termina da seguinte forma: "para trazer-nos sorte, deixe-me falar essas palavras mágicas da nossa infância: 'Abre-te sésamo', 'Era uma vez...' (A bela e a fera, 1946). Com essas palavras, o filme introduz o espírito do espectador na ficção do cinema e na magia do conto de encantamento. Já 
no conto "A Bela e a Fera ou a ferida grande demais", falta a Carla uma "magia de viver".

Também podemos perceber, no conto de Clarice, uma ruptura com o gênero do conto de fadas e em lugar de "Era uma vez..." a narrativa inicia com a palavra "começa". Nesse início alude-se à linguagem do roteiro de cinema como também no final do conto, que sugere uma cena de filme em forma de "rubrica": "(no carro andando) De repente pensou: nem me lembrei de perguntar o nome dele." (LISPECTOR, 1999, p. 105). Além dessas referências a novas formas narrativas estabelecidas no século XX, "A Bela e a Fera ou a ferida grande demais" reescreve e atualiza seu hipotexto, o conto de encantamento "A Bela e a Fera", de Beaumont, publicado no seculo XVIII. O conto de Clarice transpõe elementos do conto de Beaumont para o século XX no contexto de uma realidade social brasileira, de uma sociedade carioca, e se passa nos arredores do Copacabana Palace Hotel - uma possível alusão ao suntuoso palácio onde residia a Fera do conto de fadas. Essa atualização do antigo que atravessa o novo, como na imagem de um palimpsesto, Genette a designou de "bricolagem", - uma "maneira de fazer o novo com o velho". Nessa mesma lógica, Haroldo de Campos chamou de "transcriação ou transluciferação", uma ruptura com o texto de partida, transgredindo uma tradição em favor de uma tradução criativa que resulta numa "quebra, descontinuidade, uma dessacralização pela leitura ao revés".

Portanto, sob o texto de Clarice Lispector, "A Bela e a Fera ou a ferida grande demais", lê-se por transparência "A Bela e a Fera", de Jeanne-Marie Leprince de Beaumont e o conto "Uma xícara de chá", de Katherine Mansfield, fazendo da literatura um palimpsesto, em que, segundo Genette, um texto pode sempre ler um outro. No pergaminho que acumula textos, uns sobre os outros, o texto escrito por último fica em evidência, preservando, no entanto, traços dos primeiros, de modo que "quem ler por último, lerá melhor".

Abstract

The fairy tale "Beauty and the Beast" ("La Belle et la Bête"), by Jeanne Marie Leprince de Beaumont, published for the first time in 1756, is recreated in Clarice Lispector's brazilian short story "A Bela e a Fera ou a ferida grande demais". This Clarice Lipector's text also recriate the Katherine Mansfield's short story, "A Cup of Tea". According to the concepts of "transcriação", by Haroldo de Campos, and transtextuality, by Gérard Genette, we also consider the relation between Beaumont's fairy tale and Jean Cocteau's film La Belle et la Bête.

Key words: Clarice Lispector. Katherine Mansfield. Jean Cocteau. Transtextuality. Transcreation.

Referências

GENETTE, Gérard. Palimpsestos: A literatura de segunda mão (Extratos). Edição bilingüe. Tradução de Luciene Guimarães, Maria Antônia Ramos Coutinho. Belo Horizonte: FALE/ UFMG, 2005. Cadernos Viva Voz. 
LISPECTOR, Clarice. A bela e a fera. Rio de Janeiro: Rocco, 1999.

LISPECTOR, Clarice. A descoberta do mundo. Rio de Janeiro: Rocco, 1999.

A BELA e a Fera. (La Belle et la Bête) FRA1946. Direção: Jean Cocteau. Baseado no conto de Jeanne-Marie Leprince de Beaumont. Produção: Emile Darbon. Intérpretes: Jean Marais, Josette Day, Marcel André, Mila Parely, Nane Germon, Michel Auclair. Direção de fotografia: Henry Alekan. Direção de arte: Christian Bérard. Música: George Auric. [S.I.]: Continental Home Vídeo. DVD (aprox. 93min.), p\&b, legendado. 